\title{
Toxicological Dose Descriptor
}

National Cancer Institute

\section{Source}

National Cancer Institute. Toxicological Dose Descriptor. NCI Thesaurus. Code C158372.

A statistically derived estimate of a dose with a certain toxicological or physiologic effect in a population, based on data from a dose-response study. 